\title{
Letter. Research evaluation entities cause a shift of publication to Q1 journals
}

\author{
Félix De-Moya-Anegón
}

How to cite:

De-Moya-Anegón, Félix (2020). "Letter. Research evaluation entities cause a shift of publication to Q1 journals". Profesional de la información, v. 29, n. 4, e290431.

https://doi.org/10.3145/epi.2020.jul.31

Received on July, $31^{\text {st }} 2020$

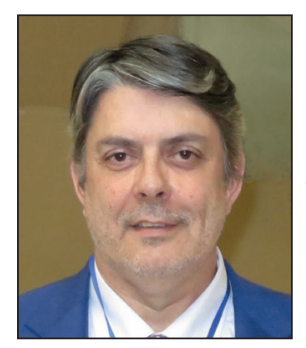

\author{
Félix De-Moya-Anegón \\ https://orcid.org/0000-0002-0255-8628 \\ SClmago Research Group, Spain \\ felix.moya@scimago.es
}

Publication frequency and the impact of world scientific production: more items in Q1

A significant characteristic of the evolution of scientific production recorded in Scopus is that there are four times more documents in first-quartile publications than in fourth-quartile publications. This proportion has remained constant throughout recent years and shows that, in all probability, despite the recently reiterated recommendations (Declaration of San Francisco and Leiden Manifesto, among others), there is a concentration of demand from authors for publication in first-quartile publications, very possibly motivated by public policies relating to science and technology around the world. This over-demand produces in principle three highly visible effects:

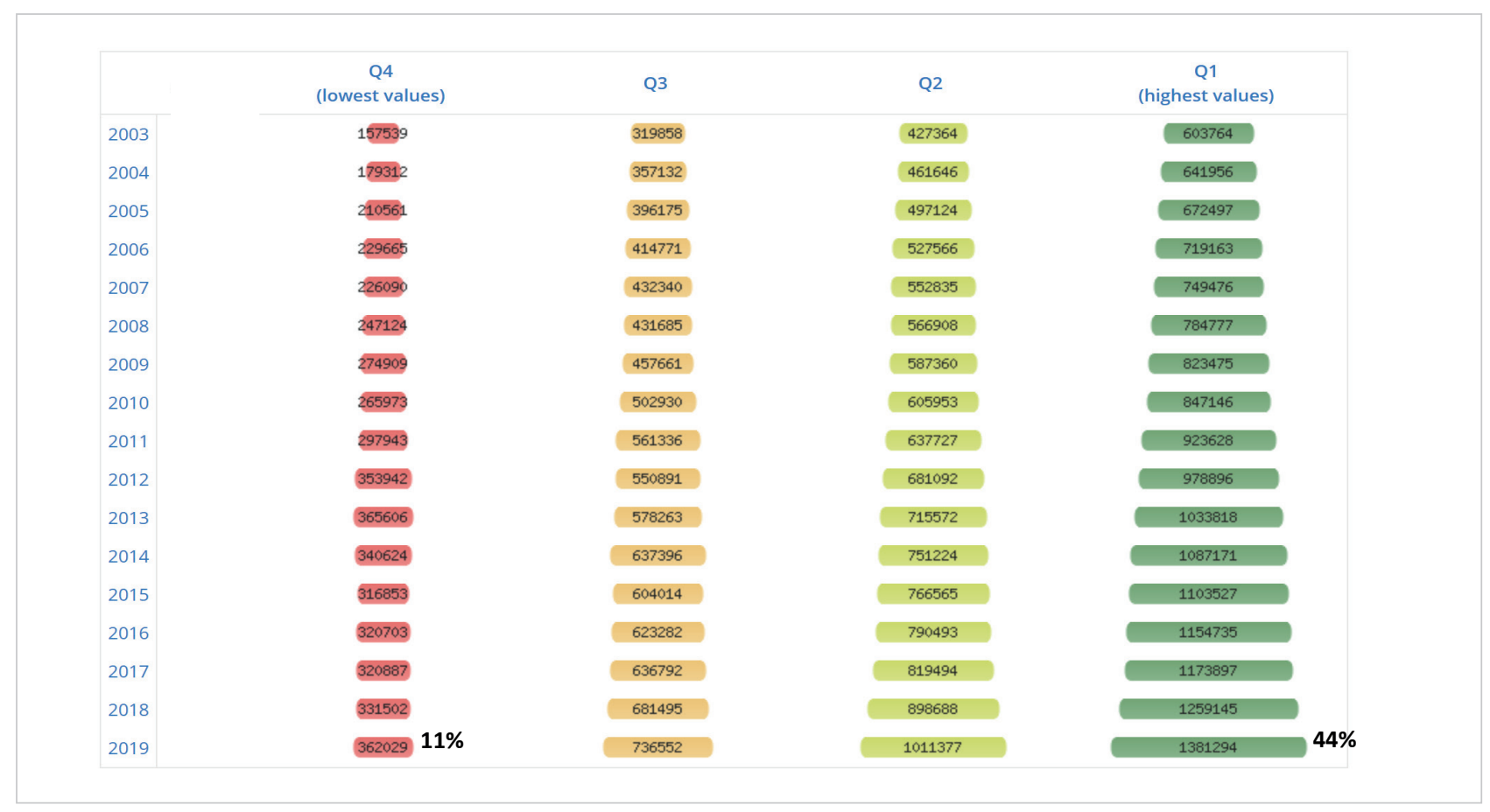

Graph 1. Evolution of the distribution of items by quartiles of publications in Scopus 


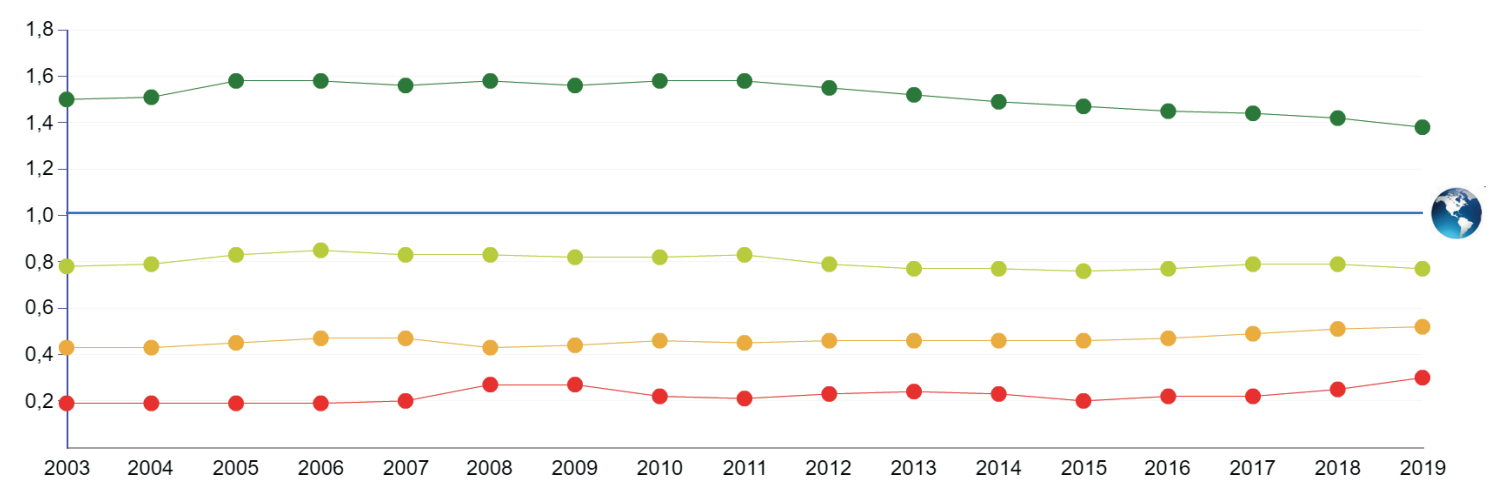

\begin{tabular}{l|l|l|l} 
Q1 & Q2 & Q3 & Q4
\end{tabular}

Graph 2. Evolution of the normalized impact by fields of the same items according to quartiles of journals

1. A growth of the space to publish works in the publications that are best placed in the international rankings (Q1). This increase in the offering by publishers is intended to adjust the editorial supply to the demand from authors, which seems to focus primarily on Q1 publications.
In the current system of scientific publications, there is a global tendency to convert the most popular journals into products managed by large publishing groups

2. This unequal distribution of items among publications of different levels produces a second effect on the distribution of normalized impact by fields of the different works according to the quartiles of the journals. Since $44 \%$ of the papers are concentrated in Q1 journals, papers published in journals in this quartile will be more likely to exceed the global average of impact. This does not make it impossible to publish high-impact papers in Q2, Q3 or Q4 journals, but it does make it statistically less likely (Graph 2).

3. A third effect of this state of affairs has to do with the distribution of business models for journals. To the extent that publications are in greater demand by authors, they tend to be absorbed in different ways by large publishing groups, considering them to represent at least sustainable business options. This circumstance seems to lie at the origin of the fact that, from the perspective of large databases, there is a greater concentration of open-access non-APC publications in the lowest quartiles. In a way, in the current system of scientific publications, there is a global tendency to convert the most popular journals into products managed by large publishing groups regardless of their origin or foundational objectives. This trend is observable whether the publications are promoted by academic institutions or scientific societies.

In short, the relationship between the use metrics of publications and the structuring of the market for scientific publications is very evident. This is probably why some of the large publishing groups (Wiley, Elsevier, Springer, etc.) have entered the part of the market with growing metrics for years. However, it is totally impossible for this global market for publications to be structured without the existence of necessary cooperators of public policy regulators in the field of S\&T. Indeed, it has not been the growth of the editorial offer that has caused this over-demand from authors, but rather the identification of part of the editorial offering by public regulators as reliable in the research evaluation processes, resulting in a concentration of demand for Q1 journals by researchers.

The identification of part of the editorial offering as reliable by public regulators in research evaluation processes has resulted in the concentration of demand from researchers for publication in Q1 journals 